\title{
LEFT-SIDED ATRIAL FLUTTER: CHARACTERIZATION OF A NOVEL COMPLICATION OF PEDIATRIC LUNG TRANSPLANTATION IN AN ACUTE CANINE MODEL
}

Sanjiv K. Gandhi, MD ${ }^{\mathrm{a} *}$

Burt I. Bromberg, $\mathrm{MD}^{\mathrm{b}}$

Richard B. Schuessler, $\mathrm{PhD}^{\mathrm{a}}$

John P. Boineau, MD

James L. Cox, $\mathrm{MD}^{\mathrm{a}}$

Charles B. Huddleston, $\mathrm{MD}^{\mathrm{a}}$
Background: Postoperative atrial flutter has been observed in approximately $10 \%$ of children undergoing lung transplantation at our institution. We hypothesized that the left atrial anastomoses made to establish pulmonary venous continuity provide the primary electrophysiologic substrates for atrial flutter. Objectives: Our objectives were (1) to determine whether the left atrial suture lines alone are sufficient to produce atrial flutter in an acute canine model of lung transplantation and (2) to characterize any resulting reentrant circuits to surgically ablate the atrial flutter. Methods: Supported by cardiopulmonary bypass, adult dogs ( $n=$ 10) underwent bilateral pneumonectomies. The left atrial anastomotic suture lines were simulated by dividing the tissue between the ostia of the transected superior and inferior pulmonary veins and closing the resulting defects. Bilateral suture lines were placed in group $1(n=6)$ to simulate bilateral lung transplantation. In group $2(n=4)$, only a left-sided suture line was placed to represent single lung transplantation. Unipolar 253point biatrial endocardial mapping electrodes were inserted via bilateral ventriculotomies. Atrial flutter was induced by atrial burst pacing, and activation sequence maps were generated. In five of six cases in group 1, a T-incision connecting the two suture lines and the mitral anulus was then made. In group 2, a single incision from the suture line to the mitral anulus was performed in each case. Burst pacing was subsequently repeated. Results: Atrial flutter could not be induced after bypass alone in any case. After simulated lung transplantation, sustained atrial flutter was reproducibly induced in 10 of 10 dogs. The mean cycle length in all dogs was $133 \pm 7$ msec. There was no significant difference in mean cycle length or activation sequence patterns between groups 1 and 2 . The reentrant circuit was confined to the left atrium. Each simulated left atrial anastomosis created a zone of conduction block around which circus movement could occur. In group 1, either suture line functioned as the central obstacle. Atrial flutter was terminated in five of five dogs in group 1 by means of the T-incision and in all four dogs in group 2 with the incision connecting the suture line to the mitral anulus. Conclusions: (1) In an acute canine model of lung transplantation, each left atrial suture line alone provides an electrophysiologic substrate for atrial flutter by creating a zone of conduction block around which circus movement can occur. (2) Extending this zone of block to the mitral anulus, together with interruption of the isthmus
From the Department of Surgery, Division of Cardiothoracic Surgery, and Department of Pediatrics, Division of Pediatric Cardiology, ${ }^{b}$ Washington University School of Medicine, St. Louis, Mo.

Supported by National Institutes of Health grants HL32257 and HL33722.

Received for publication Feb. 12, 1996; revisions requested April 8, 1996; revisions received May 7, 1996; accepted for publication May 14, 1996.
Address for reprints: Charles B. Huddleston, MD, Associate Professor of Surgery, St. Louis Children's Hospital, One Children's Place, Suite 5W24, St. Louis, MO 63110.

*Dr. Gandhi is a research fellow at Washington University. He is completing the clinical portion of his general surgery residency at St. Louis University.

J Thorac Cardiovasc Surg 1996;112:992-1001

Copyright (C) 1996 by Mosby-Year Book, Inc.

$0022-5223 / 96 \$ 5.00+0 \quad \mathbf{1 2} / \mathbf{1} / \mathbf{7 4 9 0 2}$ 
of tissue between the two suture lines present after bilateral lung transplantation, terminates the atrial flutter in this model and may have an application prophylactically at the time of lung transplantation in children to prevent postoperative atrial flutter. (J Thorac Cardiovasc Surg 1996;112:992-1001)

Pe ediatric lung transplantation is becoming a more commonly performed procedure for a variety of end-stage lung and pulmonary vascular disorders. ${ }^{1-3}$ Complications of the procedure include rejection, those consequent to the immunosuppression, and those resulting from the operative procedure, including phrenic nerve palsy, bronchial stenosis, and vascular anastomotic strictures. In addition, we recently described a high prevalence of atrial flutter (AFL), or intraatrial reentrant tachycardia, after pediatric lung transplantation. ${ }^{4}$

AFL in children without gross structural heart disease or in children after cardiac operations not involving the atria is exceedingly uncommon. Conversely, $A F L$ is a common complication after a variety of operations for congenital heart disease in which complex atrial suture lines and incisions are used. Examples include the Mustard operation for transposition of the great vessels ${ }^{5}$ and the Fontan procedure for single ventricle pathology. ${ }^{6}$ Animal model simulations of the Mustard procedure and modified Fontan repair have emphasized the importance of anatomic barriers as electrophysiologic substrates for reentry. ${ }^{7,8}$ Thus, we hypothesized that the left atrial (LA) anastomoses made to establish pulmonary venous continuity during lung transplantation provide the electrical discontinuity necessary for the creation of a reentrant circuit. The objectives of this study were to determine if the LA suture lines alone, without any hemodynamic alterations, were sufficient to permit sustained AFL in an acute canine model and to characterize any resulting reentrant circuits to surgically ablate the AFL.

\section{Methods}

Operative technique. Adult mongrel dogs weighing 30 to $35 \mathrm{~kg}(n=10)$ were anesthetized with intravenous pentobarbital sodium $(30 \mathrm{mg} / \mathrm{kg})$, intubated with a cuffed endotracheal tube, and mechanically ventilated with a Bennett MA-1 volume-cycled ventilator (Puritan Bennett Corp., Overland Park, Kan.). An adequate plane of anesthesia was maintained by intermittent infusion of 1 to $2 \mathrm{mg}$ of pentobarbital sodium. Limb lead electrocardiograms and arterial pressure were monitored with an 18-gauge catheter placed in the left femoral artery. Bilateral anterolateral thoracosternotomy was performed, the azygos vein ligated, and the heart cradled in the pericar- dium. A bipolar sensing electrode was sutured to the LA appendage and bipolar pacing electrodes were sutured to both the right atrial (RA) and LA appendages. After systemic heparinization $(1 \mathrm{mg} / \mathrm{kg})$, a $14 \mathrm{~F}$ arterial cannula was inserted into the right femoral artery and bicaval venous cannulation was performed with $28 \mathrm{~F}$ venous cannulas. Normothermic cardiopulmonary bypass was instituted. Bilateral pneumonectomies were performed. The LA anastomotic suture lines of lung transplantation were simulated by dividing the myocardium between the ostia of the transected superior and inferior pulmonary veins and closing the resulting defects in a longitudinal fashion with continuous 4-0 polypropylene suture (Fig. 1). Bilateral suture lines were placed in group $1(n=6)$ to simulate bilateral lung transplantation. In group $2(n=4)$, only a left-sided suture line was placed, representing single lung transplantation.

Bilateral ventriculotomies were created for the insertion of mapping electrodes. After excision of the mitral and tricuspid valve leaflets, two form-fitting silicone elastomer (Dow Corning Corp., Midland, MI) 253 point endocardial unipolar atrial electrodes were positioned and anchored to each anulus. An indifferent electrode was attached to the chest wall for unipolar reference.

All animals received humane care in compliance with the "Principles of Laboratory Animal Care" formulated by the National Society for Medical Research and the "Guide for the Care and Use of Laboratory Animals" prepared by the National Academy of Science and published by the National Institutes of Health (NIH Publication No. 86-23, revised 1985).

Pacing protocol. Atrial burst pacing at cycle lengths of 150 to $300 \mathrm{msec}$ was performed with the use of a programmable pulse generator (Bloom Inc., Reading, Pa.). Stimulus input was set at twice pacing threshold. Pacing was performed from both the RA and LA appendages in all experiments. Attempts to induce AFL were made (1) after bypass alone and (2) after the simulated pulmonary venous anastomoses were completed and the mapping electrodes inserted. Sustained AFL was defined as the presence of a stable tachycardia of greater than $30 \mathrm{sec}-$ onds in duration that exhibited a fixed atrial cycle length less than $200 \mathrm{msec}$. AFL was terminated either by overdrive pacing or by premature stimulation. Reproducibility was determined by reinduction of the tachyarrhythmia by use of the same extrastimulus pattern that originally induced it.

Termination of AFL. After successful induction of AFL, attempts to surgically ablate the arrhythmia were made in nine animals. In group 1 , a $\mathrm{T}$-incision connecting the two suture lines and the mitral anulus was performed. In group 2, a single incision was made contiguous with the anastomotic suture line to the mitral anulus. 

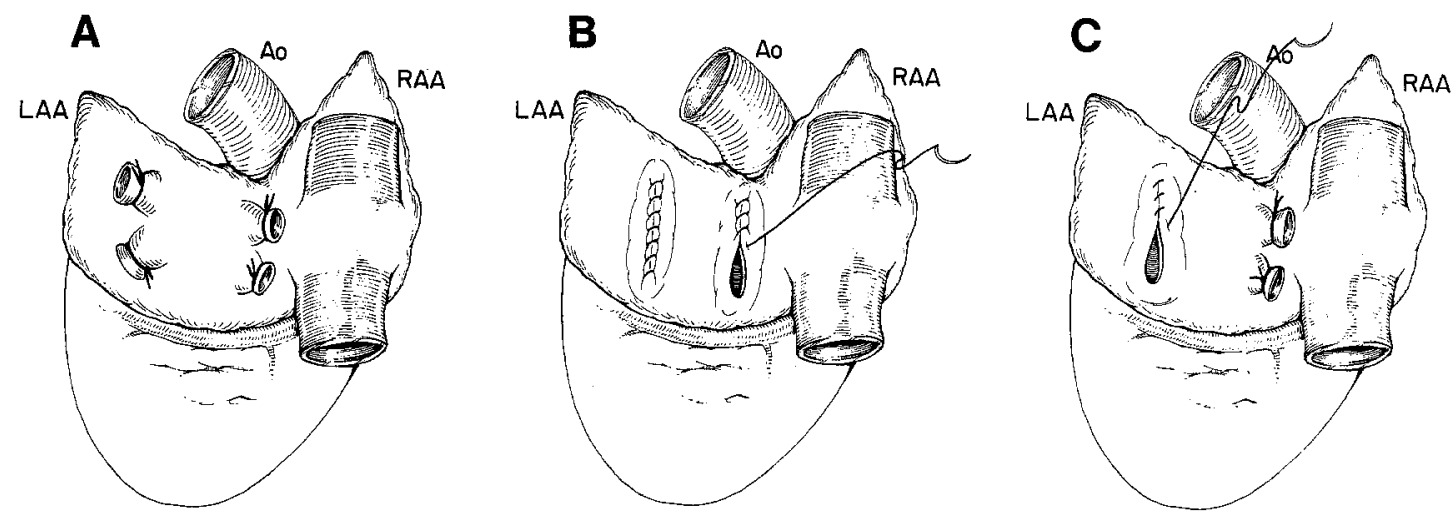

Fig. 1. Canine model of lung transplantation. After bilateral pneumonectomies were performed (A), the LA anastomotic suture lines of pulmonary transplantation were simulated by dividing the myocardium between the ostia of the transected superior and inferior pulmonary veins and closing the resulting defects. In group 1, bilateral suture lines were placed to simulate bilateral lung transplantation (B). In group 2, only a left-sided suture line was performed, representing single lung transplantation (C). $A o$, Aorta; $L A A$, left atrial appendage; $R A A$, right atrial appendage.

Table I. AFL after simulated canine lung transplantation

\begin{tabular}{cccc}
\hline Dog & $\begin{array}{c}\text { Type of } \\
\text { lung transplant }\end{array}$ & $\begin{array}{c}\text { Cycle length } \\
(\text { msec })\end{array}$ & $\begin{array}{c}\text { Cycle length } \\
\text { after incision } \\
\text { between suture } \\
\text { lines (msec) }\end{array}$ \\
\hline 1 & Bilateral & 134 & $\mathrm{n} / \mathrm{a}$ \\
2 & Bilateral & 142 & 155 \\
3 & Bilateral & 140 & 176 \\
4 & Bilateral & 134 & 167 \\
5 & Bilateral & 121 & $\mathrm{n} / \mathrm{a}$ \\
6 & Bilateral & 121 & $\mathrm{n} / \mathrm{a}$ \\
7 & Single & 131 & $\mathrm{n} / \mathrm{a}$ \\
8 & Single & 129 & $\mathrm{n} / \mathrm{a}$ \\
9 & Single & 140 & $\mathrm{n} / \mathrm{a}$ \\
10 & Single & 136 & $\mathrm{n} / \mathrm{a}$ \\
Mean \pm SD & & $133 \pm 7$ & $166 \pm 11$ \\
\hline
\end{tabular}

$S D$, Standard deviation.

Data acquisition and analysis. Atrial activation sequence data during spontaneous rhythm and during any sustained arrhythmia were obtained by simultaneously recording 253 unipolar electrograms from the endocardial multipoint electrodes. Limb lead electrocardiogram and a bipolar LA electrogram were also simultaneously recorded. Data were recorded with the use of a 256-channel computerized data acquisition and analysis system based on a VaxStation II/GPX graphics workstation (Digital Equipment Corp., Maynard, Mass.) connected to two 128-channel PDP 11/23+-based data acquisition subsystems (LKC Technologies, Inc., Gaithersburg, Md). The system is run with software (GLAS) developed in house. Local endocardial activation times were determined from the time of the maximum negative derivative $(-\mathrm{dV} / \mathrm{dt})$ of the unipolar electrogram. Data processing and three- dimensional interactive display were performed on a Silicon Graphics Iris 4D/320GTX high-performance graphic workstation (Silicon Graphics Inc., Mountain View, Calif.). Activation sequence maps were displayed as real-time images on a three-dimensional surface model of the canine atria. Two-dimensional isochronous maps were created with the use of previously outlined criteria. ${ }^{10}$

Statistical analysis. All values for each group are expressed as mean \pm standard deviation. Statistical significance of paired data was determined by Student's paired $t$ test (SYSTAT 5.0, SYSTAT Inc., Evanston, Ill.). A $p$ value less than 0.05 was considered statistically significant.

\section{Results}

Induction of AFL. Sustained AFL could not be induced after cardiopulmonary bypass alone in any case. After simulated lung transplantation, sustained AFL was reproducibly inducible in 10 of 10 dogs (Table I). The mean cycle length was $133 \pm 7$ msec. No difference in mean cycle length existed between those dogs in which bilateral LA suture lines were placed (group 1, $132 \pm 9 \mathrm{msec}$ ) and those in which only a unilateral LA suture line was created (group 2, $134 \pm 5 \mathrm{msec}, p=0.70$ ). The tachycardia was of fixed atrial cycle length and did not require ventricular participation (Fig. 2). The inducibility of AFL was not altered by the site of the pacing stimulus (i.e., RA or LA).

Features of the reentrant pathway. The reentrant circuit was confined to the LA. Each anastomotic suture line created a sufficient zone of block around which circus movement could occur. In group 1 , either suture line functioned as the central anatomic obstacle (Fig. 3). Protected isthmuses were created 

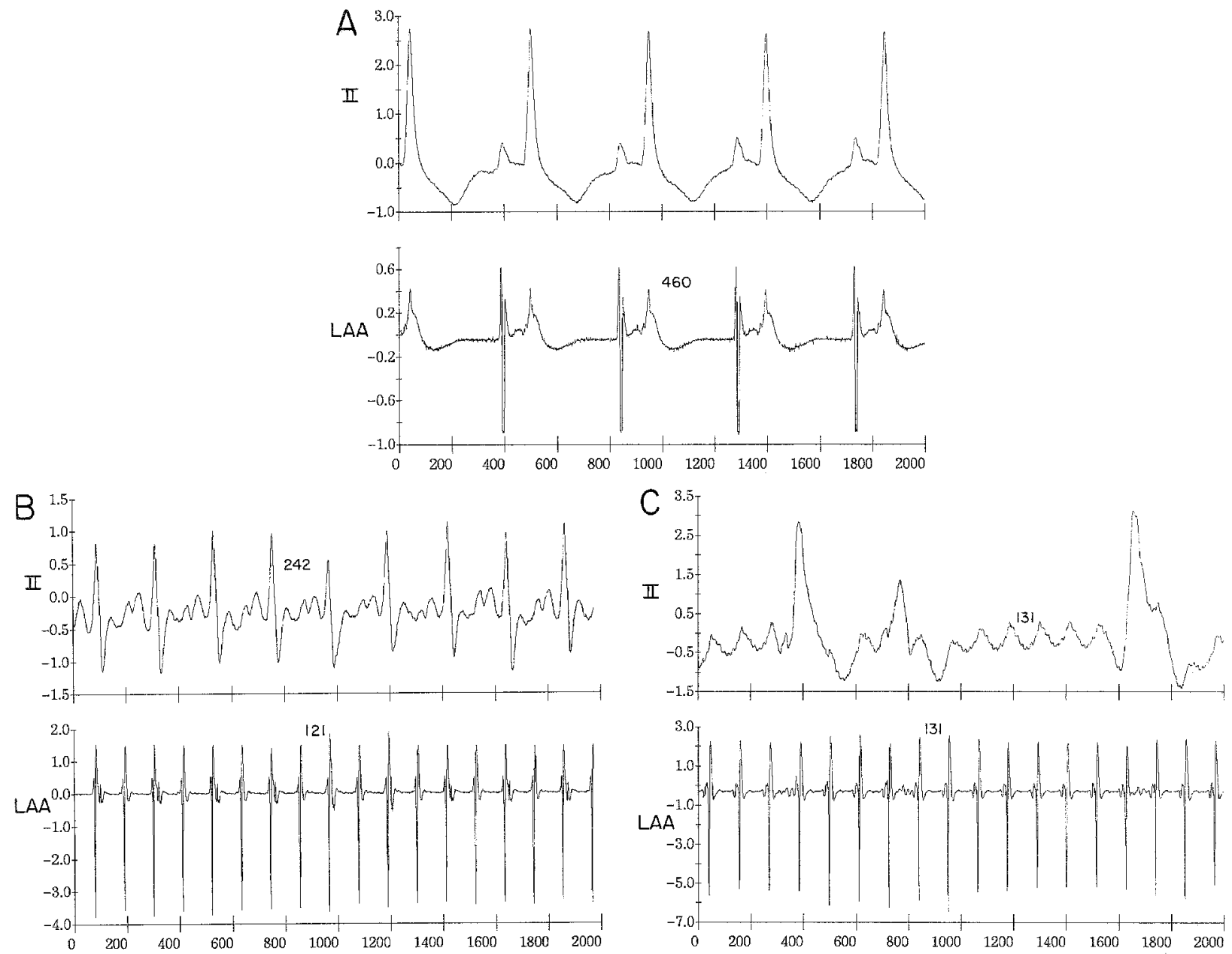

Fig. 2. Rhythms after simulated canine lung transplantation. A, Normal sinus rhythm. B, AFL with 2:1 atrioventricular nodal conduction block. $\mathrm{C}, \mathrm{AFL}$ with variable atrioventricular nodal conduction. Consecutive, nonconducted $\mathrm{p}$ waves are visible. II, Surface electrocardiogram lead II; $L A A$, left atrial appendage.

between the two suture lines and between the suture line that was the central obstacle and the mitral anulus. In group 2, the impulse revolved around the single anastomotic suture line. A circumferential zone of myocardium bounded superiorly by the suture line and inferiorly by the mitral anulus was critical for propagation of reentry (Fig. 4). No distinct zone of slow conduction was identified in either group.

Activation of the RA was passive. However, variable interatrial conduction was occasionally observed (Fig. 5). Reentrant impulses originating in the LA were not always conducted to the RA in a 1:1 fashion. This produced an irregularly irregular rhythm in the RA, whereas the LA exhibited a fixed cycle length tachycardia, typical of intraatrial reentry. Furthermore, variable interatrial conduction coupled with variable atrioventricular conduction resulted in irregular R-R intervals on the surface electrocardiogram, resembling atrial fibrillation.

Surgical ablation of AFL. On the basis of the reentrant circuits identified with the activation sequence maps, attempts were made to create lines of conduction block that would interrupt the AFL (Fig. 6). A T-incision connecting the two suture lines and the mitral anulus successfully eliminated the AFL in all five cases in group 1. In three of three cases, a single incision between the two LA suture lines not only failed to terminate AFL but resulted in a significantly longer cycle length reentrant tachycardia (mean $166 \pm 11$ msec, $p=0.001$ ) in each 

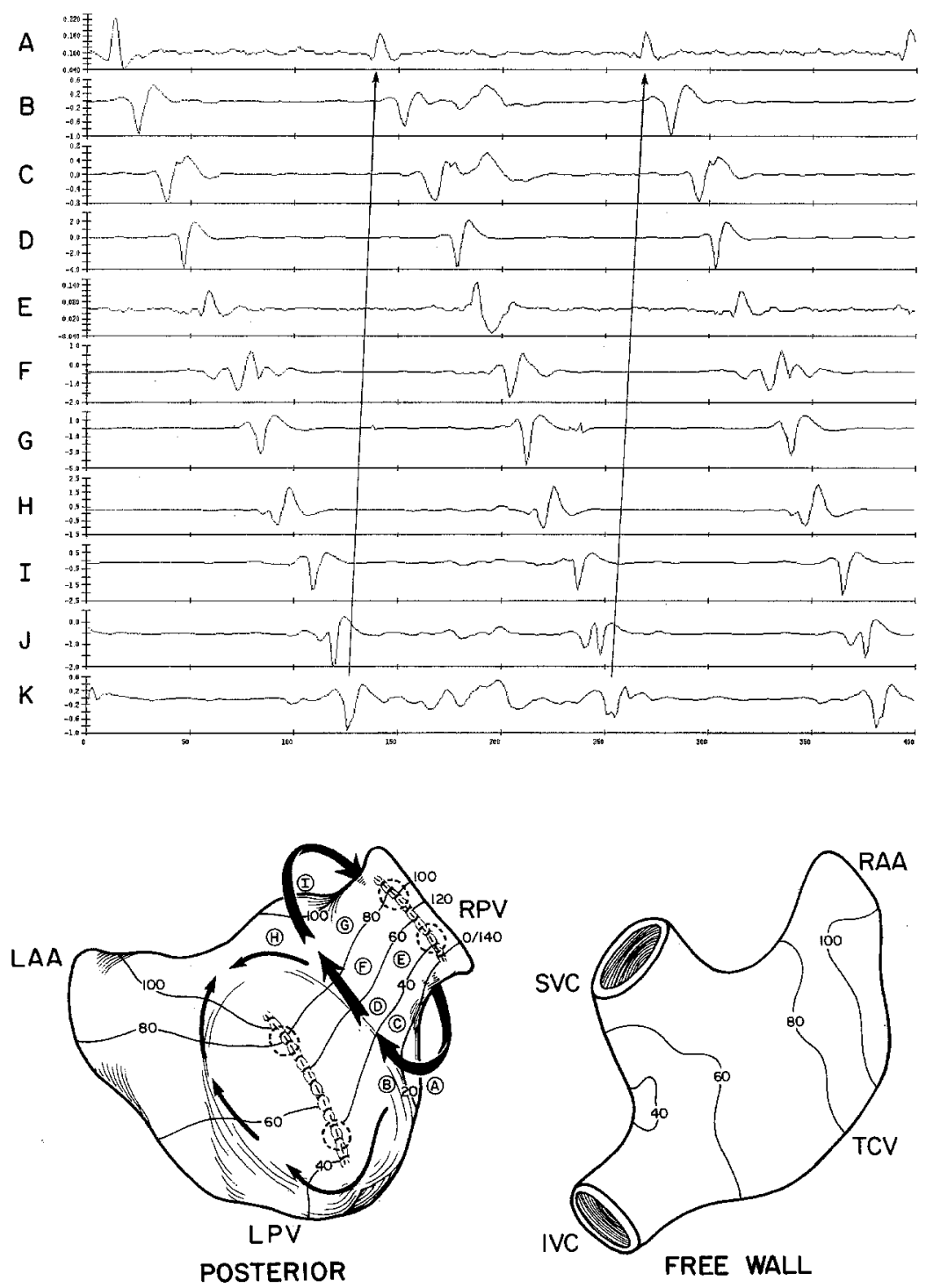

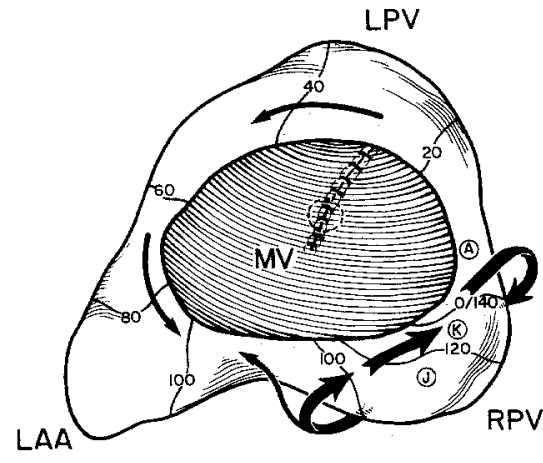

ANTERIOR

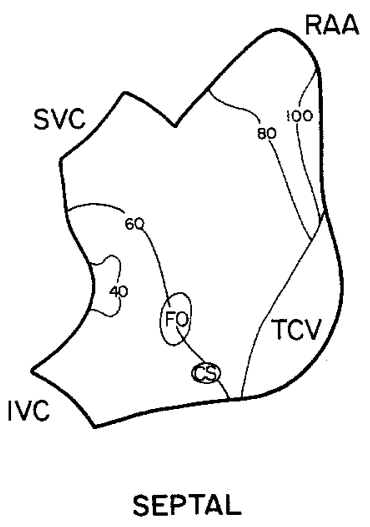

RIGHT ATRIUM

\section{LEFT ATRIUM}

Fig. 3. For legend see opposite page. 
instance. Activation sequence maps demonstrated that this incision created a larger zone of conduction block in the LA, which functioned as a central obstacle around which the reentrant wave front rotated (Fig. 7). In two of two cases, a single incision from one suture line to the mitral anulus also failed to ablate the reentrant tachyarrhythmia, because the impulse simply rotated around the other anastomotic suture line. In group 2, an incision contiguous with the LA suture line to the level of the mitral anulus was successful in terminating circus motion in four of four cases.

\section{Discussion}

Left-sided AFL. Electrophysiologic studies both in animal models and in human beings have demonstrated that AFL is a reentrant arrhythmia characterized by a stable macroreentrant loop. ${ }^{11}$ Areas of functional and anatomic block usually combine with the naturally occurring obstacles in the atria to produce a stable circuit. Most studies have localized a reentrant circuit to the RA. Rosenblueth and Garcia-Ramos ${ }^{12}$ produced stable AFL by a single intercaval lesion, which resulted in reentrant excitation around the superior and inferior venae cavae. ${ }^{12}$ In the model of Frame and associates, ${ }^{13,14}$ a Y-shaped incision placed in the free wall of the RA allowed for sustained AFL around the tricuspid anulus. RA anatomic and functional barriers have been demonstrated in numerous other animal models. ${ }^{15-17}$ Human studies have also rarely found minimal active participation of the LA in most macroreentrant arrhythmias. ${ }^{18,19}$
Circus movement around the pulmonary veins of the LA can be elicited in normal canine atria. ${ }^{18}$ However, these path lengths are too short to support stable, prolonged reentry. In chronic canine models of atrial enlargement ${ }^{19}$ and hypertrophy, ${ }^{20}$ sustained reentry around the pulmonary veins was demonstrated in a minority of cases. However, no previous animal model of AFL has shown reliably reproducible macroreentrant loops confined to the LA. In this study, placing a line of conduction block between the orifices of the pulmonary veins created an anatomic substrate large enough to permit sustained AFL. This situation is in many ways analogous to the numerous models of right-sided AFL in which the substrate is a zone of either anatomic or functional block interposed between the two caval orifices. ${ }^{15-17}$

Comparison between clinical findings and experimental results. In our report of AFL after pediatric lung transplantation, all cases occurred after bilateral sequential lung transplantation. ${ }^{4}$ Although small sample size did not permit meaningful statistical comparison, the complication was not observed in any of the 10 children who underwent single lung transplantation. However, in our canine model, the reentrant circuit clearly revolved around only one simulated LA anastomosis. The reasons for this discrepancy remain speculative. The refractory period of the dog is much shorter than that of human beings. Therefore, a shorter path length is required to sustain macroreentry. Whereas a unilateral LA anastomosis produces a sufficient region of block in the dog to produce AFL, the same may not be true in the human being, and perhaps the larger region of conduction block present after bilateral lung trans-

Fig. 3. Atrial activation sequence maps of sustained AFL after bilateral lung transplantation. The posterior and free wall surfaces of the LA and RA, respectively, are represented in the upper panel of the drawings. The anterior and septal surfaces of the LA and RA, respectively, are displayed in the lower panel of the drawings. The LA suture lines are depicted on the posterior LA surface. The dotted circles on the LA represent the ostia of the transected right and left pulmonary veins. In this case, the right-sided anastomotic suture line on the LA functions as the central anatomic obstacle around which circus motion occurs. The reentrant wave front travels in the isthmus of myocardium between the two LA suture lines $(A$ through $H$ ) and reaches the septal surface $(I)$. It then courses along the septum between the right-sided suture line and the mitral anulus $(J$ and $K$ ) and back into the isthmus between the suture lines to complete the circuit. The zone between the left-sided suture line and the mitral anulus is excluded from the reentrant loop and functions as a region of passive discontinuity. As the impulse travels in this zone, it is extinguished by the wave front that has traveled in the shorter path between the two suture lines. No conduction abnormalities are noted in the passively activated RA. Accompanying electrograms correspond to the letters $A$ through $K$. CS, Coronary sinus; $F O$, fossa ovalis; $I V C$, inferior vena cava; $L A A$, left atrial appendage; $L P V$, left pulmonary veins; $M V$, mitral valve; $R A A$, right atrial appendage; $R P V$, right pulmonary veins; $S V C$, superior vena cava; $T C V$, tricuspid valve. 

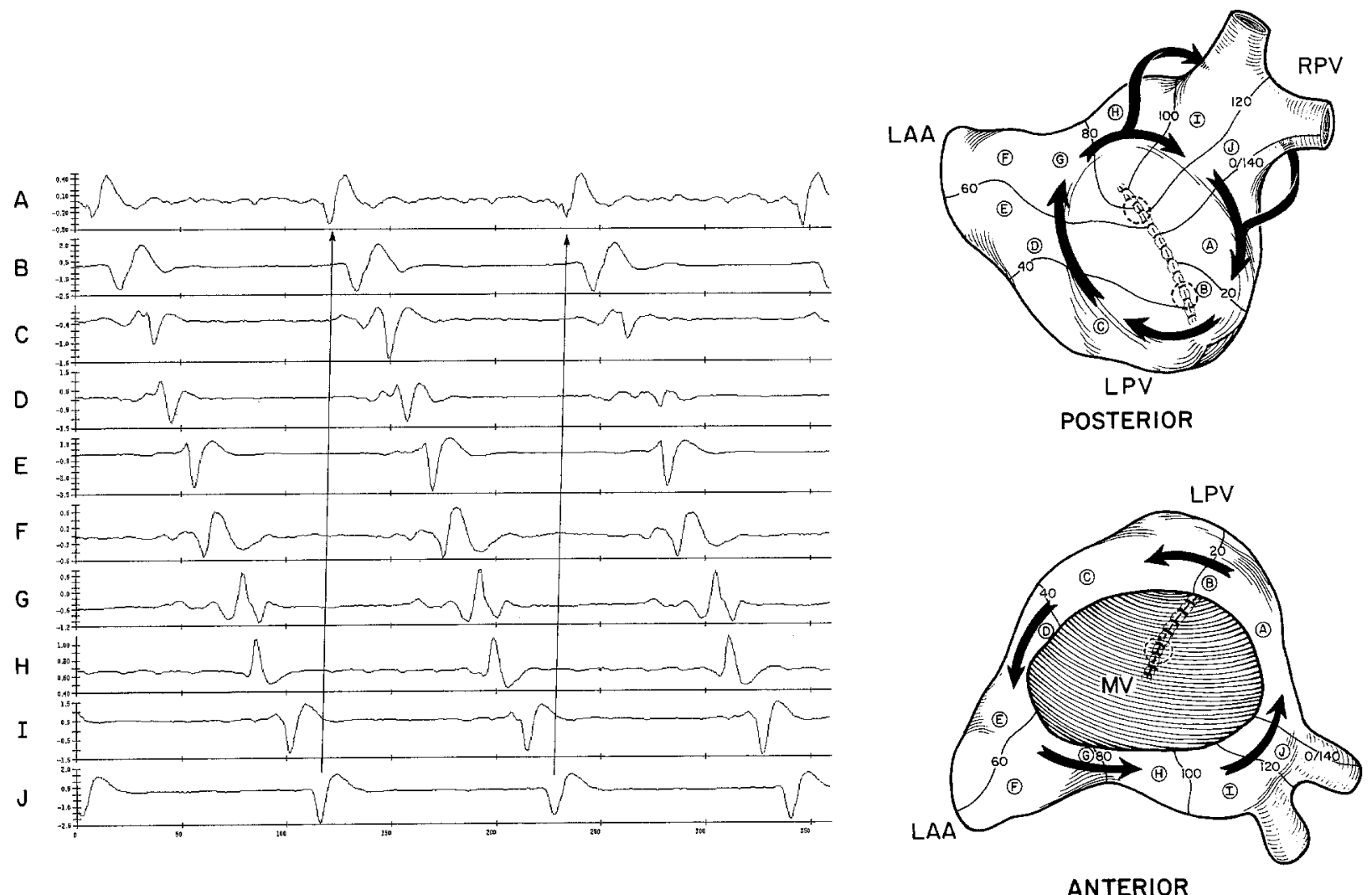

LEFT ATRIUM

Fig. 4. Atrial activation sequence maps of sustained AFL after single lung transplantation. The posterior surface of the LA is represented in the upper panel. The anterior surface is displayed in the lower panel. The LA suture line is depicted on the posterior LA surface. The dotted circles on the LA represent the ostia of the transected left pulmonary veins. Time isochrones exhibit circus motion around the anastomotic suture line. The wave front travels circumferentially between the suture line and the mitral anulus (Athrough $J$ ). It conducts uniformly around either side of the right pulmonary veins ( $I$ and $J$ ). The accompanying electrograms correspond to the letters $A$ through $J$. $L A A$, Left atrial appendage; $L P V$, left pulmonary veins; $R P V$, right pulmonary veins; $M V$, mitral valve.

plantation in human beings increases their vulnerability to this problem.

AFL mimicking atrial fibrillation. In most experimental studies of induced AFL involving either the LA or RA, the contralateral atrium has been passively activated in a 1:1 fashion. In our study, $1: 1$ conduction did not always occur to the RA from the LA reentrant circuit. Irregular or fibrillatory conduction from the LA to the RA has been described in the enlargement and hypertrophy models of canine AFL, predominantly in those cases in which the reentrant circuit revolved around the pulmonary veins. ${ }^{19,20}$ This pattern of activation, which is due to differences in refractory periods between the two atria, was termed "impure flutter" by Lewis. ${ }^{21}$ These conduction abnormalities, when combined with variable atrioventricular conduction, can produce a surface electrocardiogram with irregular R-R intervals resembling atrial fibrillation, as demonstrated both in our clinical series ${ }^{4}$ and in this study (see Fig. 6).

Clinical implications. Theoretically, the phenomenon of impure AFL may have some clinical significance in this setting. An electrocardiogram that superficially appears to resemble atrial 

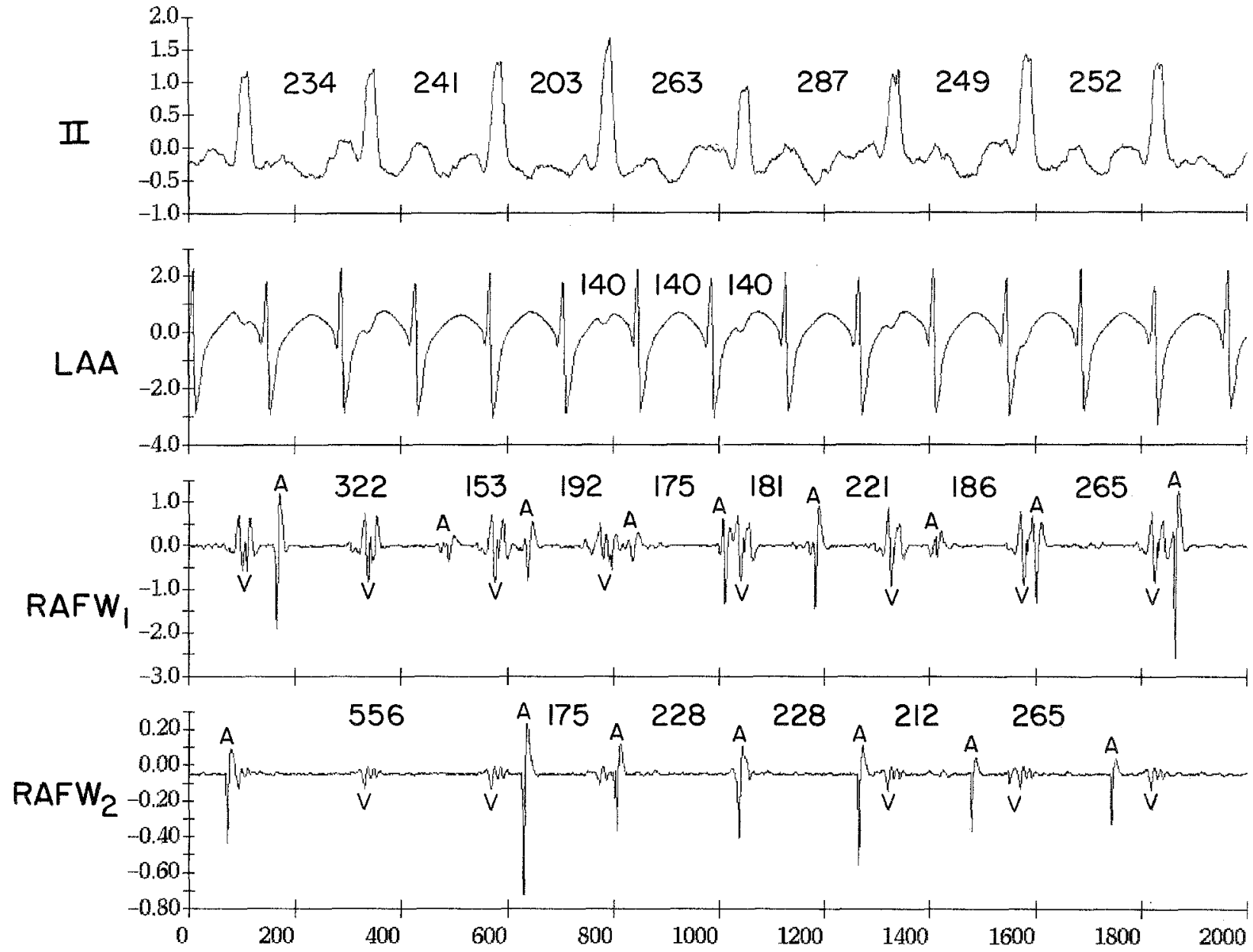

Fig. 5. Abnormal interatrial conduction. The surface electrocardiogram $(I I)$ demonstrates a rhythm with irregular R-R intervals, resembling atrial fibrillation. The bipolar reference LA electrogram illustrates AFL with a fixed cycle length of $140 \mathrm{msec}$. The other two atrial electrograms are from different positions on the RA free wall. As evidenced by the varying cycle lengths of atrial depolarizations on the RA, conduction from the LA to RA is inconsistent. This nonuniform interatrial conduction, combined with variable atrioventricular nodal conduction, is responsible for the features of the surface electrocardiogram. $A$, Atrial activation; $L A A$, left atrial appendage; $R A F W$, right atrial free wall; $V$, ventricular activation.

fibrillation may in fact be a variant of intraatrial reentry, affecting the therapy given. Temporary atrial epicardial electrodes implanted at the time of the operation may aid in the diagnosis of postoperative rhythm disorders and permit prompt termination of AFL with atrial overdrive pacing techniques.

We have again demonstrated the critical importance of surgically created barriers in the genesis of postoperative AFL, as in previous animal mod- els. ${ }^{7,8}$ No functional or hemodynamic abnormalities were required in the present study to induce AFL. Elucidation of the reentrant circuit permitted successful surgical ablation of the tachycardia. This introduces the possibility of a potential surgical modification performed prophylactically at the time of lung transplantation in children to prevent postoperative AFL.

Limitations of the study. AFL was artificially induced by burst pacing and premature extrastimu- 

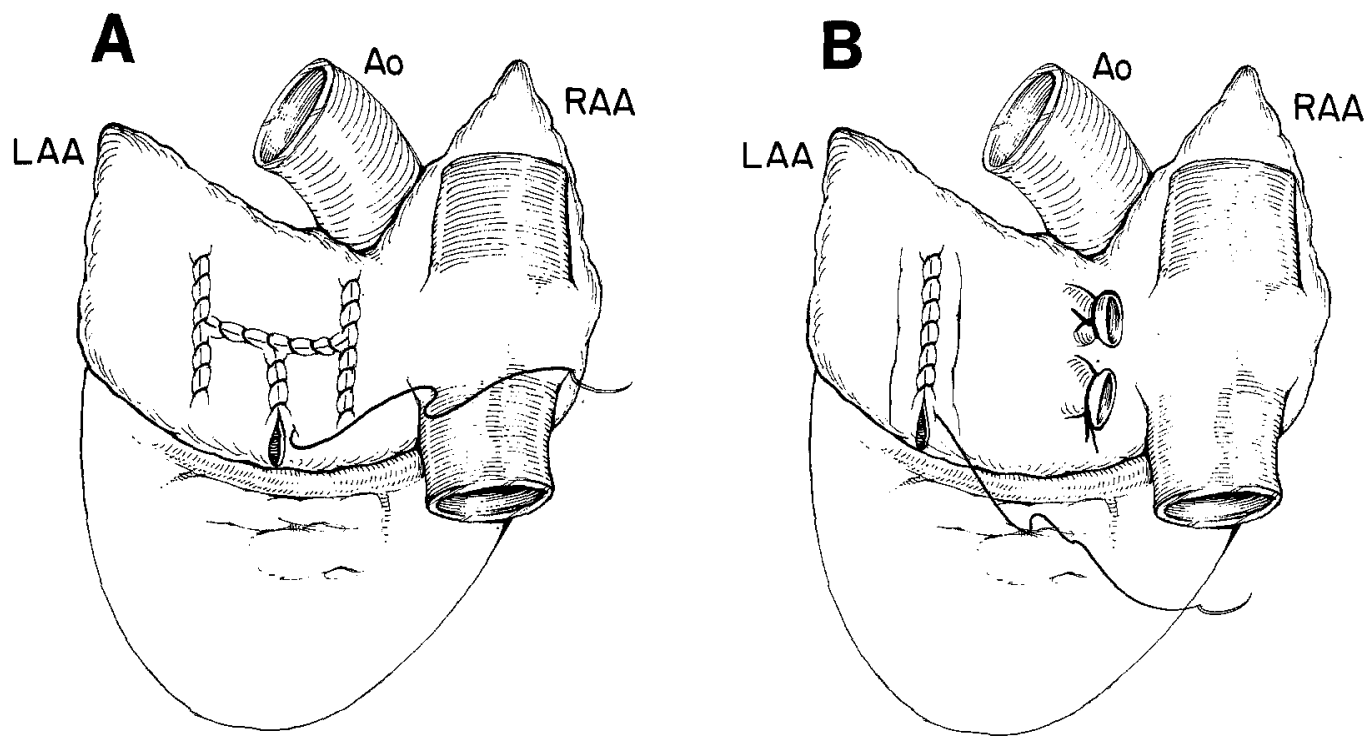

Fig. 6. Surgical ablation of AFL. A, In group 1, a T-incision was made connecting the two LA suture lines and the mitral anulus. B, In group 2, a single incision from the LA suture line to the mitral anulus was performed in each case. $A o$, Aorta; $L A A$, left atrial appendage; $R A A$, right atrial appendage.
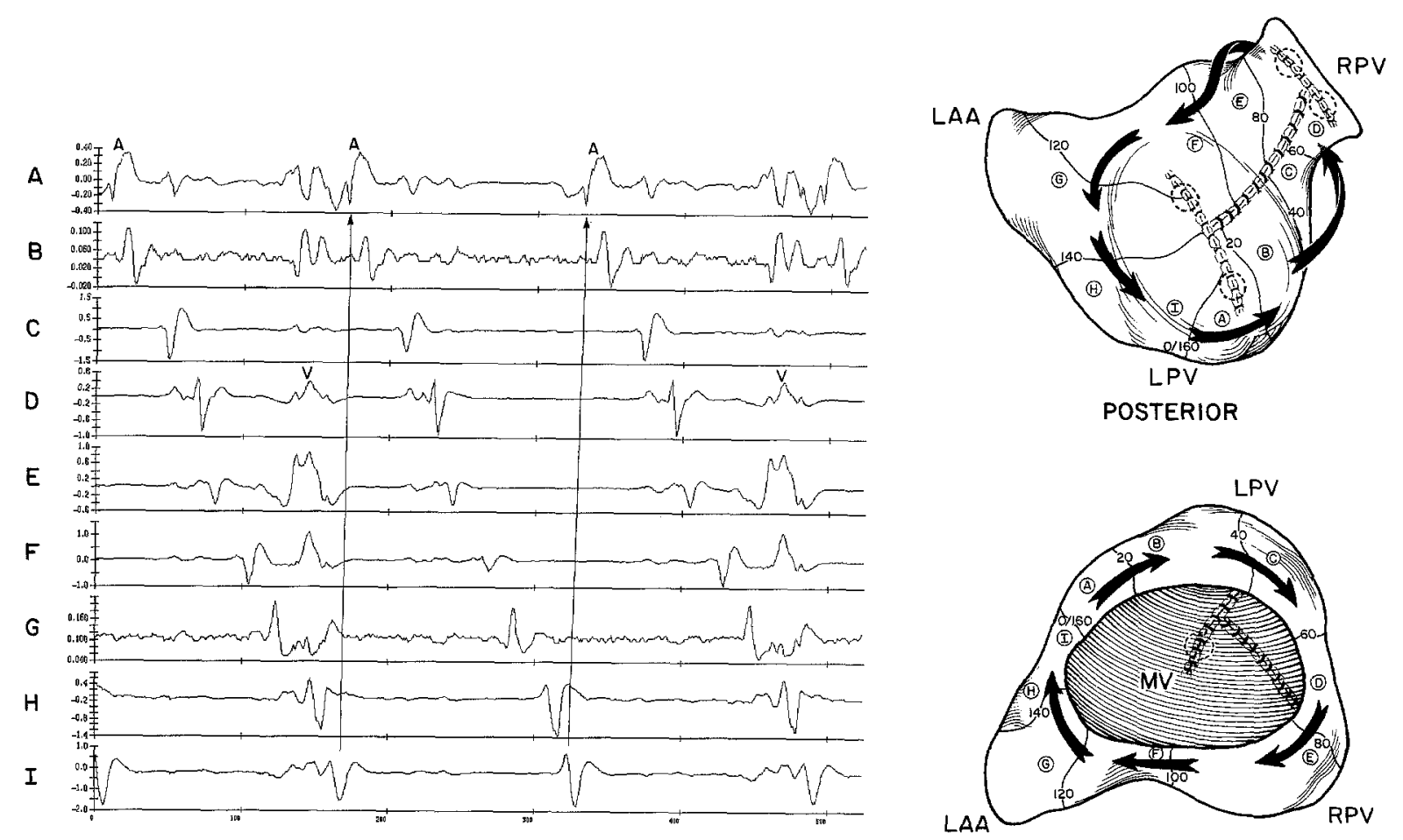

ANTERIOR

\section{LEFT ATRIUM}

Fig. 7. Atrial activation sequence maps of sustained AFL after LA suture lines connected. The LA is depicted as previously described. The LA suture lines and connecting incision are depicted on the posterior LA surface. Time isochrones are exhibited during sustained AFL induced after an incision was made between the right- and left-sided LA suture lines present after bilateral lung transplantation. The superior anatomic boundary of the reentrant circuit is the large zone of conduction block created by the combined anastomotic suture lines and the connecting incision. The inferior boundary is the mitral anulus. The accompanying electrograms correspond to the letters $A$ through $I$. $A$, Atrial activation; $L A A$, left atrial appendage; $L P V$, left pulmonary veins; $R P V$, right pulmonary veins; $M V$, mitral valve; $V$, ventricular activation. 
lation. In addition, AFL was induced during cardiopulmonary bypass after the insertion of mapping electrodes, thus eliminating any effect of atrial or ventricular filling on the induction or maintenance of AFL. These induced arrhythmias may not accurately represent spontaneous AFL after pediatric lung transplantation.

Because this was an acute study design, none of the postoperative alterations in atrial structure (such as fibrosis) present in patients who have undergone lung transplantation were present. These histologic changes may also contribute to abnormalities in atrial conduction.

\section{Conclusions}

In an acute canine model of lung transplantation, each LA suture line alone provides an electrophysiologic substrate for AFL by creating a zone of conduction block around which circus movement can occur. Extending this zone of block to the mitral anulus, together with interrupting the isthmus of tissue between the two suture lines present after bilateral lung transplantation, terminates the AFL in this model and may have an application prophylactically at the time of lung transplantation in children to prevent postoperative AFL.

We thank Bryan Turken, Tim Morris, Dennis Gordon, Duane Probst, and Donna Marquart for their expert technical assistance. We also thank the Surgical Illustrations Department of Washington University for their help in preparing the illustrations.

\section{REFERENCES}

1. Spray TM. Projections for pediatric heart-lung and lung transplantation. J Heart Lung Transplant 1993;12:S337-43.

2. Spray TM, Huddleston CB. Pediatric lung transplantation. Chest Surg Clin North Am 1993;3:123-43.

3. MacGillivray TE, Adzick NS. Lung transplantation in the pediatric patient. Chest Surg Clin North Am 1993;3:569-82.

4. Gandhi SK, Bromberg BI, Mallory GB, Huddleston CB. Atrial flutter: a newly recognized complication of pediatric lung transplantation. J Thorac Cardiovasc Surg 1996:112:984-91.

5. El-Said G, Rosenburg HS, Mullins CE, Hallman GL, Cooley DA, McNamara DG. Dysrhythmias after Mustard's operation for transposition of the great arteries. Am J Cardiol 1972;30:526-31.

6. Fontan F, Kirklin JW, Fernandez G, Costa F, Naftel DC, Tritto F, et al. Outcome after a "perfect" Fontan operation. Circulation 1990;81:1520-36.

7. Cronin CS, Nitta T, Mitsuno M, Isobe F, Schuessler RB,
Boineau JP, et al. Characterization and surgical ablation of acute atrial flutter following the Mustard procedure: a canine model. Circulation 1993;88(Pt 2):461-71.

8. Rodefeld MD, Bromberg BI, Schuessler RB, Boineau JP, Cox JL, Huddleston CB. Atrial flutter after lateral tunnel construction in the modified Fontan operation: a canine model. J Thorac Cardiovasc Surg 1996;111:514-26.

9. Branham $\mathrm{BH}, \mathrm{Bi} X, \mathrm{Cox} \mathrm{JL}$. A system for accurate interactive 3-D display of cardiac electrical activity. Institute of Electrical and Electronic Engineers. 1992;20:335-8.

10. Schuessler RB, Grayson TM, Bromberg BI, Cox JL, Boineau JP. Cholinergically mediated tachyarrhythmias induced by a single extrastimulus in the isolated canine right atrium. Circ Res 1992;71:1254-67.

11. Waldo AL. Atrial flutter: mechanisms, clinical features, and management. In: Zipes DP, Jalife J, editors. Cardiac electrophysiology: from cell to bedside. 2nd ed. Philadelphia: WB Saunders, 1995:665-81.

12. Rosenblueth A, Garcia Ramos J. Studies on flutter and fibrillation. II. The influence of artificial obstacles on experimental auricular flutter. Am Heart J 1947;33:677-84.

13. Frame LH, Page RL, Hoffman BF. Atrial reentry around an anatomic barrier with a partially refractory excitable gap. Circ Res 1986;58:495-511.

14. Frame LH, Page RL, Boyden PA, Fenoglio JJ Jr, Hoffman $B F$. Circus movement in the canine atrium around the tricuspid ring during experimental atrial flutter and during reentry in vitro. Circulation 1987;76:1155-75.

15. Boineau JP, Schuessler RB, Mooney CR, Miller CB, Wylds AC, Hudson RD, et al. Natural and evoked atrial futter due to circus movement in dogs: role of abnormal atrial pathways, slow conduction, nonuniform refractory period distribution, and premature beats. Am J Cardiol 1980;45:1167-81.

16. Boyden PA. Activation sequence during atrial futter in dogs with surgically induced right atrial enlargement. I. Observations during sustained rhythms. Circ Res 1988;62:596-608.

17. Schoels W, Gough WB, Restivo M, El-Sherif N. Circus movement atrial flutter in the canine sterile pericarditis model: activation patterns during initiation, termination, and sustained reentry in vivo. Circ Res 1990;67:35-50.

18. Schuessler RB, Boineau JP, Bromberg BI, Hand DE, Yamauchi S, Cox JL. Normal and abnormal activation of the atrium. In: Zipes DP, Jalife J, editors. Cardiac electrophysiology: from cell to bedside. 2nd ed. Philadelphia: WB Saunders, 1995:543-62.

19. Cox JL, Canavan TE, Schuessler RB, Cain ME, Lindsay BD, Stone C, et al. The surgical treatment of atrial fibrillation. II. Intraoperative electrophysiologic mapping and description of the electrophysiologic basis of atrial flutter and atrial fibrillation. J Thorac Cardiovasc Surg 1991;101:406-26.

20. Yamauchi S, Schuessler RB, Kawamoto T, Shuman TA, Boineau JP, Cox JL. Use of intraoperative mapping to optimize surgical ablation of atrial flutter. Ann Thorac Surg $1993 ; 56: 337-42$.

21. Lewis T. Observations upon flutter and fibrillation. Part IV. Impure flutter: theory of circus movement. Heart 1920;7:293332. 